\title{
Three Approaches for Shaping Safety Culture in Digital Fabrication: A Research Roadmap
}

\author{
Mikko Rajanen \\ INTERACT Research Unit, University of Oulu, Finland \\ mikko.rajanen@oulu.fi
}

\begin{abstract}
There is a lack of safety culture in digital fabrication context which can create hazards to humans, machines, and environment. We outline a research roadmap and call for action for assessing and building safety culture and safety consciousness in the digital fabrication context based on our experiences in studying this topic from practical and theoretical perspectives. Our approach for both mapping the status of safety in digital fabrication practice, as well as advocating the safety consciousness within digital fabrication scene consists of three methods, which provide insights from qualitative, quantitative, and design science perspectives. We believe that the three research methods described provide a holistic understanding on the status of, discourses about, and methods for implementing safety in Fab Labs and other makerspaces worldwide. This understanding will further help in building theories, methods, concepts, and processes for studying and shaping safety culture.
\end{abstract}

\section{CCS CONCEPTS}

- Social and professional topics;

\section{KEYWORDS}

Safety culture, Digital fabrication, Fab Lab, Making, Nexus analysis

ACM Reference Format:

Mikko Rajanen and Dorina Rajanen. 2021. Three Approaches for Shaping Safety Culture in Digital Fabrication: A Research Roadmap. In FabLearn Europe / MakeEd 2021 - An International Conference on Computing, Design and Making in Education (FabLearn Europe / MakeEd 2021), June 02, 03, 2021, St. Gallen, Switzerland. ACM, New York, NY, USA, 4 pages. https: //doi.org/10.1145/xxxxxxx.xxxxxxx

\section{INTRODUCTION}

Safety is one of the most fundamental concerns in many disciplines such as airline, nuclear energy and construction industries. In these industries the organizations actively and systematically focus on minimizing the risks of accidents and damages, develop safety rules and policies, as well as constantly train their staff in safety and safety-mindedness (see e.g. [Zhou et al., 2012]). Furthermore, safety concerns are also related to concerns of general well-being in professional work (see e.g. [Flin, 2007]), as well as

Permission to make digital or hard copies of all or part of this work for personal or classroom use is granted without fee provided that copies are not made or distributed for profit or commercial advantage and that copies bear this notice and the full citation on the first page. Copyrights for components of this work owned by others than the author(s) must be honored. Abstracting with credit is permitted. To copy otherwise, or republish, to post on servers or to redistribute to lists, requires prior specific permission and/or a fee. Request permissions from permissions@acm.org.

FabLearn Europe / MakeEd 2021, June 02, 03, 2021, St. Gallen, Switzerland

(c) 2021 Copyright held by the owner/author(s). Publication rights licensed to ACM.

ACM ISBN xxx-x-xxxx-xxxx-x

https://doi.org/10.1145/xxxxxxx.Xxxxxxx

\author{
Dorina Rajanen \\ INTERACT Research Unit, University of Oulu, Finland \\ dorina.rajanen@oulu.fi
}

related to social and environmental responsibility (see e.g. [Chen et al., 2015, Rajanen and Rajanen, 2019]). For example, in production industry the pollution, noise and other harmful effects of the process can have long-term harmful impacts on individuals, society, and environment [Chen et al., 2015]. The concept of safety culture was built based on research conducted after the Chernobyl accident, as it was identified that while safety rules and procedures were in place and the reactor should had been safe, these rules and procedures were not enough to prevent the accident, because the operators did not adhere to these safety rules and safe operating procedures, rendering them meaningless. This accident, in addition to other high-profile accidents in the aviation and nuclear industries, eventually highlighted the importance of focusing on the organizational and management impact on building and maintaining a safety consciousness in an organization in addition to the traditional organizational safety management which had for long been responsible for creating safety rules and safe procedures [Baram and Schoebel, 2007, Hudson, 2007].

The safety culture has been recognized as an important factor in many industries [Hudson, 2007]. In some disciplines (e.g. aviation, space, and nuclear industries) the safety mindset is considered an essential requirement of a professional conduct. In these disciplines, one just cannot become a professional and maintain their status as a professional, if they do not follow the safety guidelines, procedures, and have safety mindset. Therefore, in these disciplines, safety is a process of constant improvement, proactive mindset, and responsibility of all [Rajanen and Rajanen, 2020]. However, there are still multiple views on safety culture as a concept and there are contextual variations on how it is best implemented in practice [Baram and Schoebel, 2007, Flin, 2007, Hudson, 2007].

Industrial fabrication process typically involves four main phases of product development: design, manufacturing, use and disposal. In the context of traditional industrial fabrication these phases are tightly planned, controlled, and regulated from within the organization, from industry and from national and global levels to ensure that the developed product is produced, used, and disposed of in the safest way for the society in general as well as individuals [Chen et al., 2015]. Furthermore, there are strict standards, rules, and laws to ensure that safety and quality requirements are ensured in the process. However, safety issues are difficult to communicate and to enforce, and could be overlooked in various professional settings when other issues are prioritized (see e.g. [Baram and Schoebel, 2007]).

\section{SAFETY CULTURE IN DIGITAL FABRICATION}

Digital fabrication has recently emerged as a new and transformational manufacturing paradigm for businesses, communities and 
personal projects. Advancements in information, communication, and manufacturing technologies have made it possible to create novel, innovative, high-quality and personalized designs that can be shared globally, produced locally, and with a low cost as not been possible before. Fabrication tools that were previously prohibitively expensive and required trained professionals to operate are now within the reach of consumers. Digital fabrication as a concept involves various rapid prototyping and fabrication technologies such as 3D printing and laser cutting. This kind of equipment still requires at least some level of training and supervision to be used safely from the perspective of the operator, machine, production space and the environment. Machines used in digital fabrication are typically still expensive and complicated, coming with an instruction manual, safety guidelines, and material safety data sheets. While it is common that users of Fab Labs and other makerspaces are in theory required to get trained for each equipment they intend to use and to follow the safety rules, these rules are not often followed in practice, therefore indicating a lack of incorporated safety culture in digital fabrication context [Rajanen and Rajanen, 2020].

This lack of safety culture in digital fabrication context can create different kinds and levels of hazards to humans, machines, and environment. These hazards can occur when the equipment is used incorrectly, personal protection is ignored, wrong materials are used, waste is not disposed safely, and chemicals and other hazardous materials are not used safely (see e.g. [Kohtala and Hyysalo, 2015, Short and Badger, 2015]. However, currently there is a very limited amount of research reported on the topic of safety culture in digital fabrication both in practical and theoretical perspective in general, and how safety is actually managed in Fab Labs and other makerspaces (see [Baram and Schoebel, 2007, Rajanen and Rajanen, 2019,?, 2020,?]. This insight has made us look into more detail on the topic and to gather data on it with different methods such as surveys, workshops, and personal discussions with digital fabrication stakeholders.

Our discussions at the digital fabrication workshops that we have organized, the discussions with digital fabrication stakeholders from around the world at different Fab Lab events, conferences and meets where the authors were invited to talk about safety in digital fabrication, as well as pilot surveys conducted have given us opportunity to assess the status of safety culture in digital fabrication from different perspectives. These discussions and insights have strengthened our initial assumptions that there does not seem to be any kind of systematic, rigorous, or established safety culture in digital fabrication anywhere in the world and that in many cases the safety procedures, equipment and rules are established in name only, not being actually implemented, complied or enforced in practice. These observations highlight the importance of systematically mapping the current status of safety and safety culture in Fab Labs, makerspaces and other digital fabrication contexts with surveys, interviews, observations and other research methods, as well as developing the methods for not only mapping the status of safety culture in digital fabrication but also to find the best methods for introducing it in the Fab Lab community and to discuss about it using an universal vocabulary. Therefore, it would be paramount to understand the field better and knowing the current situation better would help us to construct and test out different ways to create safety culture and enforce safety rules.

Therefore, the safety culture in digital fabrication is an issue that should be studied further and in this work-in-progress paper we outline a research agenda, a research roadmap and a call for action for assessing and building safety culture in the digital fabrication context based on our experiences in studying this topic from practical and theoretical perspectives. Our holistic approach for both mapping the status of safety in digital fabrication culture, as well as advocating the safety consciousness within digital fabrication scene consists of three methods, which provide insights from qualitative, quantitative, and design science perspectives.

\section{SURVEY}

We have created a survey instrument to assess the current status of safety and safety culture in digital fabrication. With this survey instrument we want to answer the research question: To what extent the safety culture exists in digital fabrication practice? The questionnaire was adapted from the established safety culture scale in the nuclear industry context [Ostrom et al., 1993] and consists of 22 questions that map the existence of and compliance to safety rules, practices and culture of safety, such as agreeing or disagreeing with statements such as: "People work safely, even when the staff isn't looking" and "People are willing to comply with safety measures and rules". We are currently planning to conduct a global survey targeting Fab Labs and other makerspaces worldwide, in order to obtain a state-of-the-art view on the topic. The survey was piloted in the online Lab Aberto FabLab bootcamp in 2020 where the first author was invited as a keynote speaker on topic of safety culture in digital fabrication. The discussions after this keynote and during the bootcamp event with digital fabrication stakeholders ranging from managers to users further strengthened our view that safety culture has not been established in digital fabrication and that a comprehensive survey is needed to map the status of safety in digital fabrication.

These preliminary results from the pilot testing of the survey with four digital fabrication stakeholders answering the survey revealed that while the respondents unanimously considered safety as very important, people do not think about safety in their everyday interactions in the Fab Labs. For example, according to one respondent, they have higher concern of safety when they use big power tools (e.g. bandsaw) than when they use other smaller tools (e.g. soldering iron), showing that large machines with apparent danger (e.g. cutting yourself) were considered far more dangerous than tools with potential hidden dangers (e.g. toxic materials, fumes). Furthermore, the pilot survey results revealed that such a survey will be effective in mapping the practices and views of digital fabrication stakeholders on safety culture, to elicit qualitative insights and views, and that there is still much work to be done in theoretical and practical level on creating, introducing, and maintaining the safety culture in digital fabrication context. We believe that further surveys should be conducted for example on individual safety rules, their level of compliance, the use of safety equipment, and co-creation and participatory practices. Furthermore, the makerspaces have users with wide range of backgrounds 
and ages, and further surveys should be conducted among the makerspace users focusing specifically to potential differences between users of certain backgrounds or ages in their level of adherence to safety rules and their safety mindset.

\section{CO-CREATION SAFETY CULTURE WORKSHOPS IN DIGITAL FABRICATION}

While it is important to map and assess the level of safety culture across different Fab Labs and makerspaces, an equally important aspect is to find methods for engaging different stakeholders of digital fabrication into co-creating and developing the safety culture. For this end, we organized a workshop in FabLearn 2019, where we invited digital fabrication stakeholders from around the world to engage in co-creation of safety culture. We used instructional storyboard creation as means to engage the participants into insightful discussion, creation, and meaning-making on safety in digital fabrication [Rajanen and Rajanen, 2019]. With this workshop approach, we wanted to explore effective ways to communicate safety issues and to develop a safety culture among makers in their different roles as students, teachers, educators, designers, producers, academics.

The instructional storyboards proved to be a great tool for eliciting co-creation, insights and discussion about safety in digital fabrication and Fab Labs. As the digital fabrication involves people with wide variety of backgrounds, roles and interests, from around the world and having different cultural backgrounds, using storyboards in participatory co-creation workshop proved to be very easy to use and a very flexible, allowing the participants to use their imagination and to negotiate and merge their views on digital fabrication safety and communicating safety rule. During the workshop, the participants were actively discussing, planning and designing, conducting a shared meaning-making. Creating a storyboard with pen and paper is something that everybody can do, the storyboards are easy to modify, and they can be easily presented and discussed about [Rajanen and Rajanen, 2020,?].

Future workshops and collection of multimodal, qualitative, rich data could also be targeted to provide insights and generate propositions on the extent to which the participatory approaches determine changes in social responsibility, environmental responsibility, and professional responsibility which in turn reinforce a safety mindset and culture in digital fabrication (see [Rajanen and Rajanen, 2019, 2020]).

\section{NEXUS ANALYSIS}

Mapping and assessing the current status of safety culture in digital fabrication and creating participatory methods for communicating and developing safety culture are very important, but to truly develop effective theoretical and practical concepts and constructs for safety culture, we have to know how the very concept of safety itself is viewed, addressed, and conceptualized by the digital fabrication community, and what kinds of discourses there have been both in the literature and in professional practice, in order to provide a more theoretical treatment than has been provided before by the literature and to create a common vocabulary on the topic.

To analyze this perspective, we plan to apply nexus analysis. Nexus analysis is a method specifically aimed for studying complex social phenomena and to create understanding, theoretical lenses, and common vocabulary, as well as scrutinizing the historical and current discourses around the phenomena. In nexus analysis, social action and observable interactions, such as communicating and adopting safety in digital fabrication, represent the phenomenon under study in its complexity and progress [Kuure et al., 2018]. In nexus analysis, this phenomenon is called nexus of practice and it is studied using an ethnographic approach in three stages: engaging the nexus of practice, navigating it, and changing it [Scollon and Scollon, 2004]. Through these three research mechanisms, the nexus-analytic approach pertains to not only studying passively a complex practice such as the safety culture in digital fabrication, but also to influencing this culture. Furthermore, the social action under study is seen as an emerging nexus or intersection of three different types of discourses in real time and space [Iivari et al., 2017], namely interaction order, discourses in place, and historical body [Scollon and Scollon, 2004]. Interaction order views a discourse through social arrangement between people that shapes the action in question, for example, the communication of and compliance with safety rules. Discourses in place refers to social actions as being mediated by language and as existing in a physical and social space. The space can be seen as an actor by itself, for example, a Fab Lab with safety rules and safety posters clearly visible would transmit different affordances than a Fab Lab without them. Historical body refers to life experiences of a social actor, their personal habits and mental models that impact their everyday life but feel so natural to the individual that they do not even think about performing a certain action, for example being compliant or non-compliant with wearing safety equipment. Table 1 summarizes these discourses and examples in digital fabrication context. Therefore, discourses exist in interactions between people, each with their historical bodies, and this interaction being configured by emergent interaction orders in physical and social space [Scollon and Scollon, 2004].

Nexus analysis has been used successfully in the context of digital fabrication, for example to provide an in-depth study on the relationships and discourses between children and making [Iivari et al., 2017]. There is also a vast literature employing nexus analysis in educational settings such as in learning foreign languages [Kuure et al., 2018] and in early education [Wohlwend, 2008]. With the nexus analysis we want to answer the following research question: How the concept of safety in digital fabrication is being shaped and communicated in physical and social spaces?Following the successful examples of using nexus analysis in the context of digital fabrication and making (e.g. [Iivari et al., 2017, Kuure et al., 2018, Wohlwend, 2008]), we will start by conducting a literature review, as it is not always possible or convenient to access directly the discourses in physical and social space, but it is possible to study the discourses of researchers addressing the topic. This literature review will be conducted using various research databases using keywords such as "digital fabrication", "Fab Lab", "making", and "safety". The literature review will be further complemented with workshops and seminars, which will act as physical and social spaces for further discourses on building a safety culture and its related vocabulary in the context of digital fabrication. 
Table 1: Discourses in digital fabrication context

\begin{tabular}{ll}
\hline Type of discourse & Example of discourse in digital fabrication context \\
\hline Interaction order & $\begin{array}{l}\text { Communication of and compliance of safety rules as a social } \\
\text { arrangement }\end{array}$ \\
Discourses in place & $\begin{array}{l}\text { Digital fabrication space as an actor, with safety rules and safety } \\
\text { posters } \\
\text { Pistorical body }\end{array}$ \\
& $\begin{array}{l}\text { Personal experiences, habits and mental models of persons in } \\
\text { makerspace }\end{array}$ \\
\hline
\end{tabular}

\section{CONCLUSIONS}

This work-in-progress paper provides a research agenda, a roadmap and a call for action for studying and building a safety culture and safety consciousness in digital fabrication. We believe that the three research methods described here are needed to provide a holistic understanding on the status of, discourses about, and methods for implementing safety in Fab Labs and other makerspaces around the world. This understanding will further help us to build theories, methods, concepts, and processes for studying and building safety culture.

\section{REFERENCES}

Michael Baram and Markus Schoebel. 2007. Safety culture and behavioural change at the workplace-Editorial. Safety Science, 45(6), 631-636.

Danfang Chen, Steffen Heyer, Suphunnika Ibbotson, Konstantinos Salonitis, Jón Garðar Steingrímsson and Sebastian Thiede. 2015. Direct digital manufacturing: definition, evolution, and sustainability implications. Journal of Cleaner Production, 107, 615625. https://doi.org/10.1016/j.jclepro.2015.05.009

Rhona Flin. 2007. Measuring safety culture in healthcare: A case for accurate diagnosis. Safety science, 45(6), 653-667. https://doi.org/10.1016/j.ssci.2007.04.003

Patric Hudson. 2007. Implementing a safety culture in a major multi-national. Safety science, 45(6), 697-722. https://doi.org/10.1016/j.ssci.2007.04.005

Netta Iivari, Marianne Kinnula, Tonja Molin-Juustila and Leena Kuure. 2017. Multiple voices in the maker movement-a nexus analytic literature review on children, education and making. In Proceedings of the 25th European Conference on Information Systems (ECIS 2017). pp. 1919-1933

Cindy Kohtala and Sampsa Hyysalo. 2015. Anticipated environmental sustainability of personal fabrication. J. of Cleaner Production, 99, pp.333-344. https://doi.org/10. 1016/j.jclepro.2015.02.093

Leena Kuure, Maritta Riekki and Riikka Tumelius. 2018. Nexus analysis in the study of the changing field of language learning, language pedagogy and language teacher education. AFinLA-e: Soveltavan kielitieteen tutkimuksia, (11), pp. 71-92. https: //doi.org/10.30660/afinla.69208

Lee Ostrom, Cheryl Wilhelmsen and Bruce Kaplan. 1993. Assessing safety culture. Nuclear safety, 34(2), pp. 163-172.

Dorina Rajanen and Mikko Rajanen. 2019a. Co-creation of a Safety Culture in Digital Fabrication. In Proceedings of the FabLearn Europe 2019, Oulu, Finland. https: //doi.org/10.1145/3335055.3335077

Dorina Rajanen and Mikko Rajanen. 2019b. Safety Culture in Digital Fabrication: Professional, Social, and Environmental Responsibilities. In Proceedings of the FabLearn Europe 2019, Oulu, Finland. https://doi.org/10.1145/3335055.3335068

Dorina Rajanen and Mikko Rajanen. 2020a. Safety Culture in Digital Fabrication: Perceptions, Model and Co-Creation Approach. Journal of Higher Education Theory and Practice, Vol. 20(14). 2020

Mikko Rajanen and Dorina Rajanen. 2020b. Instructional Storyboard Outcomes of a Co-creation Workshop for Safety Culture in Digital Fabrication. INTERACT No 3 (October 2020) University of Oulu, Finland.

Ron Scollon and Suzie Wong Scollon. 2004. Nexus analysis: Discourse and the emerging internet. Routledge.

Short, D. B., Sirinterlikci, A., Badger, P., \& Artieri, B. 2015. Environmental, health, and safety issues in rapid prototyping. Rapid Prototyping J., 21(1), 105-110. https: //doi.org/10.1108/RPJ-11-2012-0111

Karen E. Wohlwend. 2008. Kindergarten as nexus of practice: A mediated discourse analysis of reading, writing, play, and design in an early literacy apprenticeship. Reading Research Quarterly, 43(4), 332-334.

Wei Zhou, Jennifer Whyte and Rafael Sacks. 2012. Construction safety and digital design: A review. Automation in Construction, 22, 102-111. https://doi.org/10.1016/ j.autcon.2011.07.005 